\title{
Natural-Resource Exploitation with Costly Enforcement of Property Rights
}

(Forthcoming Oxford Economic Papers)

\author{
Louis Hotte \\ Department of Economics \\ University of Ottawa \\ 200, Wilbrod st., Ottawa, Canada K1N 6N5 \\ lhott3@uottawa.ca
}

April 2004

(First draft: July 1997) 


\section{Abstract \\ Natural-Resource Exploitation with Costly Enforcement of Property Rights}

A model of resource exploitation when private ownership requires costly enforcement is developed. Enforcement costs are endogenized as the outcome of a game between a resource owner and illegal extractors. I find that two instruments are used to deter illegal extraction: policing efforts and purposeful "overexploitation" of the resource. The latter works by reducing the returns from illegal activities. Hence, even with private ownership, the marginal product of a resource worker may be below his marginal product in alternative employment. Conditions are found for which at low wage rates, further wage reductions lower profits. Those conditions are necessary and sufficient for the existence of a range of low wages characterized by a free-access equilibrium. This may explain the more frequent prevalence of free access in lessdeveloped countries. I show that higher resource prices will not lead to more free-access, but may lead to "value destruction".

Keywords: property rights; free access; enforcement costs; natural resources; income levels; economic development; economics of crime; illegal labor

JEL classification: D23, K42, O13, Q20 


\section{Introduction}

Ill-defined property rights are often cited as a major cause underlying the inefficient exploitation of natural resources. Although present in both rich and poor countries, the problem seems to be more acute in the latter ${ }^{1}$. This begs the question not only as to why property rights may be deficient on some natural resource sites, but also as to why it seems more difficult to protect those rights in less-developed economies. This analysis addresses these questions by considering both private decisions to enforce one's property rights and incentives to exploit illegally someone else's property. In this respect, this study is less about the creation of property rights where none existed before, as it is about the enforcement of those rights once established or recognized by the state.

In the proposed model, an individual who holds a title to a resource site must decide whether to engage in costly enforcement activities, and at what level, in order to exclude potential illegal extractors. The analysis attempts to determine which factors may affect these costs. More precisely, if enforcing property rights calls for the costly activity of excluding illegal extractors, one can assume that the higher the incentives to extract illegally, the costlier it is to exclude. The analysis thus borrows from the literature on the economics of crime and the supply of illegal labor in order to pin down an individual's incentives to extract illegally. This leads to the determination of an enforcement-cost function for a resource site, which will be seen to increase with the value of average product of labor on the site, and decrease with the prevailing wage rate of the economy.

The derived enforcement-cost function enters the profit function of a site owner. In equilibrium, the analysis suggests that in order to deter illegal extraction, two instruments are available for a resource owner: she can either devote more efforts in directly enforcing her property rights, or she can purposefully "overexploit" the resource as a means of lowering the returns from illegal activities. The use of this last instrument implies that, even with the institution of private property, the marginal social yield of a resource worker may be below the value of his marginal product in alternative employment. Conditions are then given for which profits from a resource site may actually decrease following a reduction in the wage rate. These conditions turn out to be necessary and sufficient for the existence of a positive threshold level of

\footnotetext{
${ }^{1}$ World Bank (1992, Chapter 3).
} 
the wage rate below which it is prohibitively costly to protect one's property from illegal extraction. Hence, within this range of low wage rates, an owner will abandon his site to a free-access exploitation. This suggests an economic rationale for the more frequent prevalence of free access in low-income economies, which differs from other oft-mentioned factors such as differences in technology, culture, legal institutions, etc.

The model is also used to verify Demsetz's (1967) conjecture which states that an increase in resource value is likely to lead to a better delineation of property rights. It is shown how, within the model's framework, an increase in resource price does not lead an owner to abandon his site to a free-access exploitation. The demonstration makes use of the fact that with a new, higher resource price, an owner can replicate the previous situation, i.e. one with a lower price, as far as illegal extractors are concerned. He can do so, again, by resorting to an increased exploitation of the resource. This result may have a more general relevance than the present one. Indeed, whenever the costs of enforcing private property are important, an owner may resort to some form of "destruction of value" in order to save on these costs.

One branch of the literature on property rights offers various reasons explaining the different tenure regimes in effect across regions or periods. Some authors contend that it may be related to a society's culture, religion, legal institutions, etc. (North, 1990; Cohen and Weitzman, 1975; Firmin-Sellers, 1995) Others have suggested that securing those rights may be the result of a cost-benefit analysis on the part of the private owner. If there are costs associated with property enclosure, ownership will be claimed only as long as the benefits from exploitation exceed the costs of enclosure. Anderson and Hill (1975) advocate such economic incentives underlying the determination of property rights. In their formulation, enclosure movements are mostly driven by exogenous technological progress in enforcement technology, and by changes in output prices. Within the context of an open international economy, their analysis, however, can hardly account for the differences in property rights regimes observed between industrialized and less-developed economies. Field's (1989) approach gets closer to providing an explanation by observing that an increase in population can lead to a reduction in exclusion costs through the increased supply of labor. But his analysis does not explicitly account for individuals' incentives to extract illegally. Taking those incentives into account adds new insight.

The present analysis was initially motivated by some studies in international trade. Indeed, after having observed that property rights are not 
as well defined in less-developed countries, a few theoretical inquiries have considered the effects of trade between industrialized regions with well defined property rights, and less industrialized regions with deficient property rights (see, e.g., Chichilnisky, 1994; Brander and Taylor, 1997a, 1997b, 1998a, 1998b; Tornell and Velasco, 1992). These studies took tenure regimes in both regions as exogenous to the analysis. In this respect, a more fundamental issue was being sidesteped which could affect some of their conclusions about the overall effects of trade: they do not account for the causes of the different prevailing tenure regimes. The model proposed here could be used to fill this gap.

The paper is organized as follows: In Section 2, an enforcement-cost function is derived and then partial-equilibrium exploitation decisions for a resource-site owner are determined. Section 3.1 considers the effects of varying the wage rate on the profit function and on decisions to enforce property rights. The effects of increasing the resource price are considered in Section 3.2. The conclusion presents a discussion of the results and proposes some extensions.

\section{The model}

A model will be developed which leads to a property rights enforcement-cost function. But before doing so, a few remarks may be helpful. First, the fact that nobody extracts illegally on the property does not imply that enforcement activities are absent; much to the contrary, it implies that these activities are important enough to completely discourage any desire to extract illegally. Moreover, the possibility of partially enforced property rights is not excluded here a priori; it corresponds to a situation in which the owner considers that it is in her interest, given the costs of excluding illegal extractors, to let a certain amount of the site's output be illegally captured. But it will be seen that in the proposed model (in particular under the assumption of a large number of identical illegal extractors), a profit maximizing site owner will not opt for a partial enforcement of her property rights in equilibrium. She finds it optimal to either completely eliminates all incentives to extract illegally or, if enforcement costs are too large, she abandons the site to a free-access exploitation. ${ }^{2}$ It is in this last case that the institution of

\footnotetext{
${ }^{2}$ Instances of partial enforcement appear in Helsley and Strange (1994), Milliman (1986), Sutinen and Anderson (1985), Clarke et al. (1993) and Crabbé and Long (1993).
} 
private property will not be sufficient to prevent free access from occurring in equilibrium. ${ }^{3}$

Let us assume a community inhabited by a total of $n$ workers and a non-specified number of owners. The latter may comprise natural-resource site owners as well as any other type of productive capital ownership. Each worker is endowed with one unit of inelastically supplied labor time, which must be allocated between legitimate and illegitimate activities. ${ }^{4}$ Legitimate activities pay the going wage rate $w$. Illegitimate activities take the form of illegal extraction on a resource site, the return to which will be precisely defined below.

Of interest to us is the behavior of the owner who holds a title to a resource site. In order to maximize returns, she must decide on how many workers to hire at the going wage rate for the direct exploitation of the resource, and on how much enforcement activities to undertake in order to contain illegal extraction. This includes the possibility of relinquishing the site to a free-access exploitation where enforcement activities are absent.

In order to concentrate on the problem faced by the owner of a site, let us consider a partial-equilibrium setting in which both the wage rate and the resource price are exogenous. The owner and illegal extractors ${ }^{5}$ engage in a sequential game where the owner plays first by simultaneously choosing the amount of workers $l$ hired to exploit the resource and the level of enforcement $\lambda$ used to contain illegal extraction. In making these choices, she anticipates the outside extractors' reaction to them. Each worker constitutes a potential illegal extractor and they all simultaneously choose the amount of time to spend extracting, $\theta_{i} \in[0,1], i=1, \ldots, n$, after having observed $l$ and $\lambda$. Note that workers hired by a site owner are among of the $n$ workers/illegal extractors that live in the surrounding community, and that due to the assumed large value of $n$, it is considered prohibitively costly for an owner to contract with every single one of them.

Tietenberg (1996, p. 293) provides a short interpretation.

${ }^{3}$ Additionnally, private decisions to have well-defined property rights may not be a socially efficient outcome as there are now costs involved in defining property rights. On the efficiency of private decisions to enforce property rights, see Anderson and Hill (1975), de Meza and Gould (1992), Lasserre (1994) and Field (1989).

${ }^{4}$ See Ehrlich (1973), p. 528, for a discussion of the choice between taking part in both legitimate and illegitimate activities, or specializing in one type of activity.

${ }^{5}$ For ease of exposition, the term "illegal extractors" includes "potential illegal extractors" since the equilibrium enforcement level may completely deter illegal activities by some individuals. 
In order to proceed, it is first necessary to describe the nature and effects of the enforcement level $\lambda$. Two interpretations are proposed below which turn out to be analytically equivalent for risk-neutral illegal extractors. The context should determine which of the two interpretations is the most appropriate.

\subsection{The effects of enforcement activities on the returns to illegal extraction}

One way to interpret $\lambda$ is to say that it represents the probability of detecting an illegal extractor. Once detected, an illegal extractor gets a penalty, the magnitude of which is a fixed proportion $\gamma$ of the income derived from illegal activities, expressed in monetary terms. Imagine that under the normal conditions of a perfectly legal exploitation of the resource, the returns from a unit of labor time is $v$. Then the return for an individual who spends a proportion $\theta_{i}$ of his unit of labor time in illegal activities will be $(1-\gamma) \theta_{i} v$ with probability $\lambda$, and $\theta_{i} v$ with probability $1-\lambda$, which sums up to $(1-\lambda \gamma) \theta_{i} v$ in expected return.

Another way to interpret $\lambda$ is to say that it represents the loss of productivity due to avoidance activities. ${ }^{6}$ It may indeed be quite unrealistic to assume that an outsider can be as productive as a legitimate worker on a site. In order to avoid detection, an outsider may need to jump the fence each time he enters or leaves the site, he may decide to extract only after dark, he may only exploit the more remote areas of the site, he may not be able to use noisy or cumbersome equipment such as a tractor, a motor boat, a chain saw, etc. The severity with which the illegal extractor's productivity will be affected by avoidance activities will certainly increase with the site owner's level of enforcement efforts. The returns to illegal extraction can thus be represented as $(1-\lambda) \theta_{i} v$. This interpretation differs from the previous by the absence of the penalty factor $\gamma$, but it leads to the same results. ${ }^{7}$

The first interpretation will be retained for the ensuing analysis because

\footnotetext{
${ }^{6}$ This is the interpretation proposed in Hotte, Long and Tian (2000).

${ }^{7}$ This interpretation also differs from the previous by the fact that the "effective" amount of time spent extracting illegally is given by $(1-\lambda) \theta_{i}$ here, while it is given by $\theta_{i}$ in the previous case. As will be seen below in the case of a natural resource, this will affect the returns from a unit of labor, denoted by $v$ here. But for both cases, there will not be any illegal extraction in equilibrium, as will be shown shortly. For this reason, both interpretations lead to the same outcome.
} 
it is more general and it seems more realistic since implicit in the act of avoiding detection is the presence of a threat of punishment once caught.

Where the enforcement of property rights is backed by the state (or any other third-party organisation), this penalty may take the form of imprisonment, a fine, a loss of reputation, physical abuse, etc. In any case, it will be assumed that the owner of a site cannot recover the amounts appropriated illegally.

Since the owner is the first mover, we begin by deriving outsiders' reaction to the choice of $l$ and $\lambda$.

\subsection{The decision to extract illegally}

Workers-illegal extractors are assumed risk-neutral and thus maximize the expected value of their income. Since $\theta_{i}$ represents the fraction of labor time spent extracting illegally, legal work brings home an income of $\left(1-\theta_{i}\right) w$ with certainty. To be more general, we allow for the probability of detection to depend on the amount of time spent extracting illegally, i.e. $\lambda=\lambda\left(\theta_{i}\right)$ with $\lambda^{\prime}\left(\theta_{i}\right) \geq 0$. Hence, expected income is given by $E(y)=\left(1-\theta_{i}\right) w+(1-$ $\left.\lambda\left(\theta_{i}\right) \gamma\right) \theta_{i} v .{ }^{8}$ In the present analysis, it will be natural to assume that $v$ equals the value of average product of labor time on the site. ${ }^{9}$ One may have noticed that as far as illegal extractors are concerned, the problem proposed here is in many respects similar to the problem of free-access exploitation developed in Dasgupta and Heal (1979), and that the main difference resides in the fact that the illegal extractor must face a probability of being fined if detected.

Let $h(x)$ be the total steady-state output function for the site's natural

\footnotetext{
${ }^{8}$ See Becker (1968), Ehrlich (1973), and Heineke (1978) for similar representations of an individual's decision to participate in illegitimate activities when there is a probability of apprehension and punishment. $\gamma$ may be larger or smaller than one depending, for instance, on the criminal justice system, the observability of the amount stolen, etc. The analysis does not consider the issue of third party enforcement (North 1990, Chapter 7). Once an outsider has been reported to the authorities by a site owner, he is automatically punished and the amount of the fine goes to the treasury, or he is imprisoned. Lump-sum and infinitely large fines are ruled out as they are often believed to be either inefficient or socially unacceptable. On the magnitude of fines, see, for instance, Stigler (1970), Friedman and Sjostrom (1993) and Van Rijckeghem and Weder (1997).

${ }^{9}$ Productivity differences due to investments or better technology by the owner are assumed away. See Besley (1995) for theory and evidence on property rights and investment incentives.
} 
resource, where $x$ denotes the total amount of labor time spent exploiting the site, i.e. $x=l+\sum_{i=1}^{n} \theta_{i}$. We have,

Assumption 1 The steady-STATe Production function The steadystate output function for a renewable natural resource on a given site is assumed to satisfy

$$
\begin{aligned}
& h(0)=0, \\
& h^{\prime}(x)>0 \text { for } x \in(0, \tilde{x}) \text {, where } \tilde{x} \leq+\infty, \\
& h^{\prime \prime}(x)<0, \\
& h(x) \text { is bounded above by } h(\tilde{x})=\bar{h} .
\end{aligned}
$$

Remark: If only congestion effects are taken into account, then $\tilde{x}=+\infty$ and $h^{\prime}(x)$ is always positive (as in Dasgupta and Heal, 1979:56). To borrow from Smith (1968), we will thus say that the resource exhibits only "crowding externalities". But if we take into account resource stock effects and the possibility of depletion, as is generally the case when considering a renewable resource, then the steady-state output initially increases with $x$, reaches a maximum sustainable output $\bar{h}$ at some finite input level $\tilde{x}$, and then decreases to zero for finite $x$, say at $\bar{x}$, as the stock becomes depleted (as in Brander and Taylor 1997a, 1997b, 1998a, 1998b and Brown 2000). In this case, following Smith (1968) again, the resource will be said to exhibit "stock externalities". ${ }^{10}$

In order to clarify the exposition, a worker's average product on a site is represented as $\phi(x)=h(x) / x$. Hence, once he has observed the choice of $l$ and $\lambda$ by the owner of the site, the $j$ th illegal extractor will maximize his expected income $E\left[y_{j}\right]$ by choosing $\theta_{j}$, given $\theta_{i}, i \neq j$, in order to solve the following problem:

$$
\max _{\theta_{j}} E\left[y_{j}\right]=w\left(1-\theta_{j}\right)+\left(1-\lambda\left(\theta_{j}\right) \gamma\right) \theta_{j} p \phi\left(l+\sum_{i \neq j} \theta_{i}+\theta_{j}\right),
$$

where $p$ is the market price of a unit of the resource.

The equilibrium decisions of the outsiders must therefore satisfy, for an interior solution, the following set of first-order conditions for $j=1, \ldots, n$ :

$$
(1-\lambda \gamma)\left[p \phi(x)+\theta_{j}^{*} p \phi^{\prime}(x)\right]-\lambda^{\prime}\left(\theta_{j}\right) p \phi(x)=w .
$$

\footnotetext{
${ }^{10}$ See Clark (1976) or Smith (1968) for a derivation of the steady-state output of a renewable resource which takes into account the dynamic interactions between the resource stock, its growth rate, and harvesting efforts.
} 
The right-hand side of the above relation gives the loss in income due to a marginal unit reduction in legal work, i.e. it represents the opportunity cost of labor time. The left-hand side represents the net gain in expected income resulting from a marginal unit increase in illegal activities. In equilibrium, of course, the marginal gain must equal the marginal loss. ${ }^{11}$

A symmetrical equilibrium, where $\theta_{i}^{*}=\theta^{*}$, for all $i=1, \ldots, n$, will satisfy:

$$
\left(1-\lambda\left(\theta^{*}\right) \gamma\right)\left[p \phi\left(l+n \theta^{*}\right)+\theta^{*} p \phi^{\prime}\left(l+n \theta^{*}\right)\right]-\lambda^{\prime}\left(\theta^{*}\right) \gamma \theta^{*} p \phi\left(l+n \theta^{*}\right)=w .
$$

Consider now the limiting case where $n$ tends to infinity. Brooks et al. (1999) have shown that since total profits are finite on the site $(h(x)$ being bounded above), Gordon's (1954) result of period-by-period rent dissipation can be relied on. ${ }^{12}$ For an illegal extractor, rent dissipation means that the expected return from illegal activities must be equal to the legal wage rate i.e., for sufficiently large $n,{ }^{13}$

$$
\left(1-\lambda\left(\theta^{*}\right) \gamma\right) p \phi\left(l+n \theta^{*}\right)=w .
$$

In other words, as $n$ becomes sufficiently large, $\theta^{*}$ becomes infinitesimally small, with the result that the expected income gain from a marginal unit increase in extraction becomes $(1-\lambda \gamma) p \phi\left(l+n \theta^{*}\right)$ : the individual extractor has no noticeable impact on average productivity. But the fact that $\theta^{*}$ is small does not imply that illegal extraction is not a significant problem for the owner. This is because $n$ is large so that $n \theta^{*}$ could be large. Note that in the case where property rights are absent, the removal of an owner corresponds to $\lambda=0$ and $l=0$ which yields, once inserted into relation (4), $p \phi\left(n \theta^{*}\right)=w$; we recover the classic outcome of a free-access resource with total rent dissipation. Moreover, even in the presence of an owner, complete rent dissipation also obtains if the detection technology is characterized by a probability of detection that vanishes at the limit where people spend a negligible amount of time extracting illegally, i.e. $\lim _{\theta_{i} \rightarrow 0^{+}} \lambda\left(\theta_{i}\right)=0$. In this

\footnotetext{
${ }^{11}$ Note that the first-order conditions imply that $\partial \theta_{j}^{*} / \partial w<0$ and $\partial \theta_{j}^{*} / \partial \lambda<0$. These comparative static results are consistent with empirical investigations on incomegenerating illegal activities which state that (Heineke 1978): an increase in the probability of being detected, or in the going wage rate, reduces the individual supply of illegal labor. See also Ehrlich (1973) on this.

${ }^{12}$ It can also be verified that the symmetrical equilibrium is unique and stable. See Varian 1992, p. 287

${ }^{13}$ In order to interpret relation (4), one may refer to Fig. 1 by substituting variable $l$ with $l+n \theta^{*}$, and $w$ with $w /(1-\lambda \gamma)$.
} 
case, property rights cannot be profitably enforced, a result which leads to the following proposition:

Proposition 1 When faced with a large number of identical illegal extractors, a necessary condition for a site owner to enforce his property is for the detection technology to respect the following property:

$$
\lim _{\theta_{i} \rightarrow 0^{+}} \lambda\left(\theta_{i}\right)>0 .
$$

In the ensuing analysis, we will thus assume that condition (5) holds. Note that this assumption introduces a discontinuity in the probability of detection since as soon as one engages in illegal activities, the probability of detection jumps from zero to a strictly positive value. In the present context, enforcement boils down to choosing the level of $\lim _{\theta_{i} \rightarrow 0^{+}} \lambda\left(\theta_{i}\right)$, which we henceforth simply denote as $\lambda .{ }^{14}$

Equation (4) determines how much outside extraction $n \theta^{*}$ will occur for any choice of $l$ and $\lambda$ by the owner. It represents the implicit reaction function of the illegal extractors that the site owner will take as given in making her decisions. This reaction function indicates that the owner of a site can reduce incentives to extract illegally with two different instruments: she can either increase her efforts $\lambda$ at detecting outsiders, or she can hire more labor to exploit the resource, thereby decreasing the value of average product of labor on the site. The latter instrument has a dissuasive effect on outsiders because it lowers the returns to illegal activities. Hence, it can be asserted that the overexploitation of a resource can be used as a substitute to enforcement activities as a means of dissuading outsiders. How this is to be done in equilibrium is the object of the following section.

\subsection{The decision to exploit and enforce a site}

We have assumed, up to now, that an illegal extractor could take as given the enforcement level $\lambda$ chosen by the owner of a site, without specifying how that level could be achieved. We now wish to introduce an enforcement

\footnotetext{
${ }^{14}$ By proposition 1, this assumption is obviously crucial for the present analysis to be valid. It seems reasonable if one reckons that the passage from absolutely no illegal activity to a small amount of it involves a sudden jump to a non-negligible detection probability, such as would be the case with boundary patrols or cameras. (I am grateful to an anonymous referee for raising this issue.)
} 
output function which assigns an enforcement level $\lambda$ to any combination of enforcement labor and capital. In line with the above discussion regarding the interpretation of $\lambda$, the function is to be refered to as the detection function.

Assumption 2 The Detection Function Let e represent the level of enforcement activities. The probability of detection is given by $\lambda=f(e)$ where

1. The detection function $f(e)$ has the following properties:

$$
\begin{aligned}
& f(0)=0 \\
& f(e) \leq 1 \text { for all } e \geq 0 \\
& f^{\prime}(e)>0 \text { and } f^{\prime \prime}(e) \leq 0 \text { for all } f(e)<1 .
\end{aligned}
$$

2. The level e of enforcement activities can be attained by hiring a combination of enforcement capital $\left(k_{e}\right)$ and labor $\left(l_{e}\right)$ at unit cost $r$ and $w$ respectively, i.e. $e=g\left(k_{e}, l_{e}\right)$, where the function $g\left(k_{e}, l_{e}\right)$ is homogeneous of degree one.

Remarks: Since $g\left(k_{e}, l_{e}\right)$ is homogeneous of degree one, the unit cost of $e$ is a constant function of $r$ and $w$, and will be denoted $c(r, w)$. Moreover, $f(e)$ being monotone increasing, the detection function $\lambda=f\left(g\left(k_{e}, l_{e}\right)\right)$ is a homothetic transformation of $k_{e}$ and $l_{e}$, which exhibits constant or decreasing returns to scale since $f^{\prime \prime}(e) \leq 0$. (Varian 1992, 18 and 67) Examples of enforcement activities include direct supervision time by the owner and her family, hired guards, or physical capital such as fences, ditches, patrol boats and horses, cameras, guns, etc.

An owner's problem can now be conveniently expressed as choosing the amounts of labor $(l)$ and enforcement activities $(e)$ in order to maximize profits, while taking into account the induced level of illegal extraction $n \theta^{*}$ given by equation (4), i.e.

$$
\max _{e, l} \pi=\left(p \phi\left(l+n \theta^{*}\right)-w\right) l-c(r, w) e,
$$

s.t. $(1-\gamma f(e)) p \phi\left(l+n \theta^{*}\right)=w$ and $n \theta^{*}>0$ if $(1-\gamma f(e)) p \phi(l)>w$, $n \theta^{*}=0 \quad$ otherwise.

The first-order conditions for an interior solution with $n \theta^{*}>0$ are

$$
\frac{\partial \pi}{\partial l}=p \phi\left(l+n \theta^{*}\right)-w+p \phi^{\prime}\left(l+n \theta^{*}\right)\left(1+\frac{\partial\left(n \theta^{*}\right)}{\partial l}\right) l=0,
$$




$$
\frac{\partial \pi}{\partial e}=-c(r, w)+p \phi^{\prime}\left(l+n \theta^{*}\right) \frac{\partial\left(n \theta^{*}\right)}{\partial e} l=0
$$

Proposition 2 Under assumptions 1 and 2 and the presence of an arbitrarily large number of identical potential illegal extractors, the owner of a natural resource site will choose to completely deter outside extraction, i.e. $n \theta^{*}=0$. The resulting combination of labor $(l)$ hired to exploit the resource, and enforcement activities (e), will be such that

$$
(1-\gamma f(e)) p \phi(l)=w
$$

Proof: It is shown in i) that as long as $n \theta^{*}>0$, the owner's profits increase by hiring an additional worker. Therefore, since $n \theta^{*}=0$ whenever $1-$ $\gamma f(e) p \phi(l) \leq w$, it is shown in ii) that the owner will choose a strict equality.

i) Since $\theta_{i}$ cannot be negative, $n \theta^{*}$ is bounded from below by zero. Hence, from (4), we get $\partial\left(n \theta^{*}\right) / \partial l=-1$ when $n \theta^{*}>0$, and $\partial\left(n \theta^{*}\right) / \partial l=0$ when $n \theta^{*}=0$. But since positive profits imply that $p \phi(x)-w>0, \partial \pi / \partial l$ must be strictly positive when $n \theta^{*}>0$ and $\pi>0$. As a result, for any given $e, l$ must be such that $n \theta^{*}=0$ in equilibrium.

ii) Once $n \theta^{*}$ equals zero, further increases in $l$ cannot be offset by reductions in $n \theta^{*}$. Therefore, for given $e, p \phi(x)$ starts decreasing with increases in $l$ and we get $(1-\gamma f(e)) p \phi(l)<w$, i.e. the expected gain from illegal extraction becomes strictly smaller than its cost. This cannot be a profit maximizing equilibrium either since $e$ could be reduced until the equality is re-established, while keeping illegal extraction at zero. QED

The intuition behind this result is that as long as some illegal extraction takes place, condition (4) holds and thus the value of average product of workers is constant and equal to $w /(1-\lambda \gamma)$. Given $\lambda$, adding one worker will just reduce $n \theta^{*}$ by one unit, such that $l+n \theta^{*}$ remains constant and condition (4) is respected. Now if profits on the site are positive, the value of average product of this additional worker must be above the wage rate, thereby increasing the owner's profits. ${ }^{15}$

\footnotetext{
${ }^{15}$ Crabbé and Long (1993) have similarly proposed that in equilibrium, poachers in a fishery will be completely deterred in a setting which is referred to as "open access for poachers", a situation equivalent to an infinite amount of poachers in the present analysis. In their analysis, Crabbé and Long take enforcement costs as given, and thus do not account for the possibility that these costs be endogenously determined by the level of exploitation of the resource.
} 
Expression (9) yields an implicit relation between $e$ and $l$, as chosen in equilibrium by the owner of a site. For convenience, let us denote the level of enforcement activities that minimizes enforcement costs, for any choice of $l$, as $e(l ; w, p, \gamma)$, and let $\psi(\cdot)$ be the reciprocal function of $f(e)$. We have,

$$
e(l ; w, p, \gamma)=\psi\left(\frac{1}{\gamma}\left(1-\frac{w}{p \phi(l)}\right)\right)
$$

where, according to assumption $2, \psi^{\prime}(\cdot)>0, \psi^{\prime \prime}(\cdot) \geq 0, \psi(0)=0$.

When one looks at equation (10), the roles played by both $w$, the economy's prevailing wage rate, and $\gamma$, the proportion of the fine, should be emphasized: they bear on incentives to extract illegally by individuals in the entire community and as such, must be taken as given by the owner of a site. The relation describes how equilibrium enforcement activities decrease with the ratio of the wage rate to the value of average product of labor on the resource site. Once they are equal, i.e. $w=p \phi(l)$, incentives to extract illegally vanish and enforcement costs are nil - a situation equivalent to free-access exploitation.

The owner's profits in (6) can now be expressed as

$$
\pi=p h(l)-w l-c(r, w) \psi\left(\frac{1}{\gamma}\left(1-\frac{w}{p \phi(l)}\right)\right) .
$$

Notice how the choice of labor not only affects the direct returns from exploitation, $p h(l)-w l$, but also indirectly affects enforcement costs through its effect on $\phi(l)$. Both values being dependent on the number of workers employed, $l$ essentially constitutes the owner's sole choice variable.

The first-order condition is ${ }^{16}$

$$
\frac{\partial \pi}{\partial l}=p h^{\prime}\left(l^{*}\right)-w-c(r, w) \psi^{\prime}\left(\frac{1}{\gamma}\left(1-\frac{w}{p \phi\left(l^{*}\right)}\right)\right) \frac{w}{\gamma p} \frac{\phi^{\prime}\left(l^{*}\right)}{\phi\left(l^{*}\right)^{2}}=0 .
$$

The last term of the derivative denotes the unit marginal gain in reduced enforcement expenditures associated with an increase in labor hired on the

\footnotetext{
${ }^{16}$ Profits will generally not be everywhere concave in $l$. But we can verify that if positive profits are possible at all, a global maximum exists that respects first-order condition (12) and lies strictly between $l_{P}$ and $l_{F}$ (see Fig. 1). Indeed, it is easy to show that $\partial \pi / \partial l>0$ for all $l \leq l_{P}$, and that $\pi=0$ at $l_{F}$. The verification is complete with the observation that profits are continuous in $l$.
} 
site. This reduction in enforcement expenditures is due to the lower average productivity of labor which translates into a lower return from illegal activities. Since $\phi^{\prime}\left(l^{*}\right)<0$, this effect is positive and implies that in equilibrium, $p h^{\prime}\left(l^{*}\right)<w$. Hence the following proposition:

Proposition 3 The owner of a site employs workers whose marginal productivity value is lower than the wage rate.

This result is illustrated in Fig. 1. Note that it obtains despite the fact that all benefits and costs accrue to the owner of the resource, i.e. no illegal activity occurs in equilibrium. Depending on the exact form of the production and detection functions, it could even be beneficial, given the wage rate and the resource price, for the owner of a site to employ labor with negative marginal productivity. The analysis suggests that the equilibrium amount of labor hired by an owner can fall anywhere between $l_{P}$, the "neo-classical" level of exploitation with costlessly and perfectly defined and enforced property rights, i.e. $p h^{\prime}\left(l_{P}\right)=w$, and $l_{F}$, the free-access level of exploitation of the resource, in which all rents are exhausted, i.e. $p \phi\left(l_{F}\right)=w \cdot{ }^{17}$

The intuition for the above result can be expressed as follows. At the point where the value of labor's marginal product equals the wage rate, adding a worker increases revenues by the same amount as its direct cost, the wage rate. Enforcement expenditures, however, can be reduced since the now lower average productivity makes illegal extraction less attractive. Therefore, it pays to hire that extra worker. Each further addition to the labor force will yield less than the wage rate and this, at an increasing rate, as there are decreasing returns to labor; conversely, if the gains in reduced enforcement costs occur at a constant or diminishing rate, then an employer will hire more workers until the two effects exactly offset each other. An interior solution for $l^{*}$ will exist whenever the marginal gain in reduced enforcement costs equals

\footnotetext{
${ }^{17}$ See Gordon (1954) for an early technical analysis on the exploitation of open access natural resources, Hardin (1968) for an intuitive approach on the "Tragedy of the Commons" or Baumol and Oates (1988, pp. 26-28) for a concise presentation. As mentioned by Ostrom (1990), this theory abstracts from the fact that individuals may organize to improve the efficiency of exploitation of a resource subject to free access. Once a site becomes exploited by an organized group, it can no longer be referred to as free-access property but rather as common property. But then this group must devote resources to enforce its exploitation rules and exclude others. In this respect, the site has effectively become enclosed and can be treated as a privately owned site. See also Barzel (1989, p. 71) on this.
} 


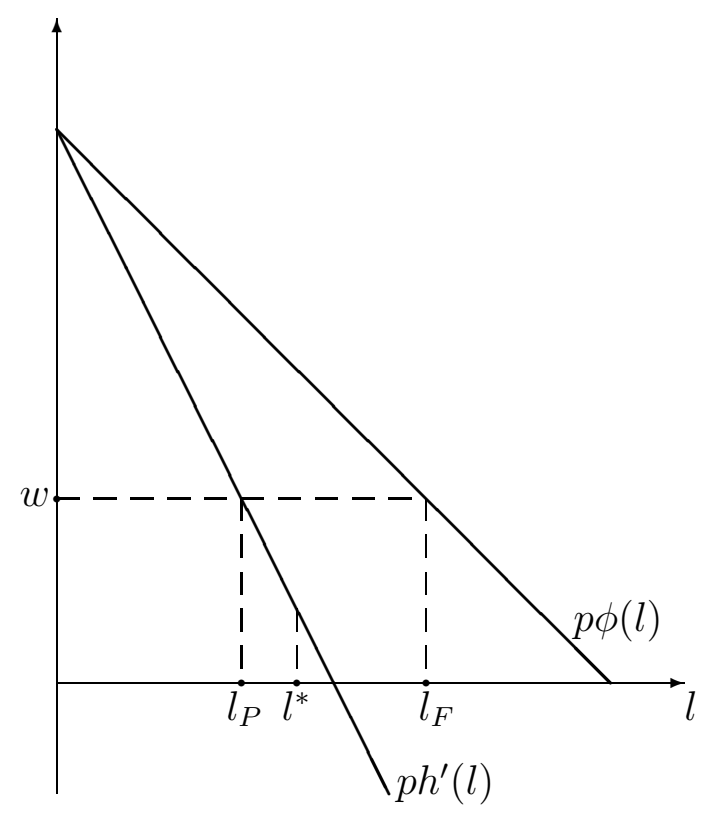

Figure 1: Exploitation of a privately owned resource with costly enforcement

the marginal loss of increased production at a level below $l_{F}$. If the marginal enforcement gain and production loss curves do not meet before $l_{F}$ is reached, then it will never be optimal for an individual to exclude outsiders. Note that the existence of an interior solution is not sufficient to have enforcement; an additional condition is that profits be positive at that point.

We therefore observe that with costly exclusion of outsiders, the level of exploitation of the resource will exceed that for which labor's marginal productivity value equals the wage rate, even though no illegal extraction takes place. Hence the following corollary:

Corollary 4 When exclusion is costly, private ownership does not guarantee a socially efficient allocation of workers between the different sectors of an economy.

It becomes clear from Fig. 1 that an owner will resort to a sort of "overexploitation" of the resource in order to economize on enforcement costs. This result may carry interesting implications, as in the context of international trade for instance. As have noted Chichilnisky (1994) and Brander and Taylor (1997a, 1998a), some countries may export resources because of a so-called "apparent comparative advantage" due to the absence of property rights in the resource sector. That is, because the resource is subject to a 
regime of free-access, it is over-exploited and its excessive supply drives its autarkic price below the world price in terms of manufactures. Brander and Taylor (1997a, 1998a) have shown that this may result in actual losses from trade. What the present analysis suggests is that this apparent comparative advantage may still obtain in the presence of private ownership since overexploitation of the resource, aimed at deterring illegal activities, may still drive the price below the world price. The possibility of losses from trade thus remains. ${ }^{18}$

It may be interesting to note that in their study of range land exploitation on Southwestern Indian reservations in the United States, Johnson and Libecap (1980) have observed the use of overgrazing as a means of discouraging potential entrants. They attribute this suboptimal situation to the authorities' refusal to grant formal recognition of land ownership to large herders. The emphasis is thus put on the role of a third party, i.e. the authorities. The foregoing analysis suggests that one should also consider the role played by private decisions to enforce property rights and by incentives to extract illegally from other individuals on the reservation. Note also that the effectiveness of detection activities could depend on the choice of commodities produced by the owner. This was pointed out in Cheung (1970) where it is observed that in Tripolitania, more valuable almond production was replaced by cattle raising because almond trees were more difficult to police than cattle, since the latter can be driven home at night.

\section{The effects of the wage rate and resource price on decisions to enforce property rights}

The foregoing analysis allows us to perform comparative-static experiments in order to determine the role played by relevant parameters such as an economy's prevailing wage rate and resource price. Let us begin with the wage rate.

\footnotetext{
${ }^{18}$ See Hotte, Long and Tian (2000) which extends the analysis to a study of international trade by introducing a simplified version of the present model in a general equilibrium setting.
} 


\subsection{Comparative static experiments on the wage rate}

Making use of the envelope theorem, equilibrium profits will change with the wage rate according to

$$
\frac{\partial \pi^{*}}{\partial w}=-l^{*}+c(r, w) \psi^{\prime}(\cdot) \frac{1}{\gamma p \phi\left(l^{*}\right)}-\frac{\partial c(r, w)}{\partial w} \psi\left(\frac{1}{\gamma}\left(1-\frac{w}{p \phi\left(l^{*}\right)}\right)\right)
$$

A reduction in the wage rate can be decomposed into three effects: the classic one ${ }^{19}$ is to increase profits by $l^{*}$ through a reduction in the cost of labor exploiting the site; but it also reduces profits by $c(r, w) \psi^{\prime}(\cdot)\left(1 / \gamma p \phi\left(l^{*}\right)\right)$ since a lower wage reduces the opportunity cost of illegal activities and thus calls for more enforcement; and finally, profits increase by $(\partial c(r, w) / \partial w) \psi(\cdot)$ due to the now lower wage cost of agents hired to detect outsiders.

In spite of an apparent indeterminacy about the net effect on profits of a decrease in the wage rate, one can find intuitive sufficient conditions for the second effect to prevail as the wage rate becomes small. These conditions turn out to be necessary and sufficient for the existence of a positive wage rate below which enforcement does not pay.

Proposition 5 Assume that positive profits are achievable for some range of wage rates.

a) As the wage rate becomes sufficiently small, further reductions in the wage rate will result in lower profits if the resource exhibits stock externalities and the following condition holds

$$
p \bar{h}<c(r, 0) \psi\left(\frac{1}{\gamma}\right)
$$

b) There exists a threshold level of the wage rate, say $\underline{w}$, below which positive profits are ruled out, if and only if the resource exhibits stock externalities and condition (14) holds. The resource is thus abandoned to a free-access exploitation for any wage rate comprised in the range $(0, \underline{w})$.

Remark: It may be argued that as the wage rate goes to zero, an owner can hire an arbitrarily large number of enforcers at virtually no cost. Technically, this supposes that $\lim _{w \rightarrow 0} c(r, w)=0$, so that condition (14) would

\footnotetext{
${ }^{19}$ That is, Hotelling's lemma is restored if we assume costlessly and perfectly enforced property rights, or $c(r, w)=0$.
} 
never hold. But this turns out to be a strict assumption. If one assumes, for instance, that $g\left(k_{e}, l_{e}\right)$ is a CES technology (see Assumption 2), then $c(r, 0)$ is generally strictly positive (Varian 1992, p. 56) and condition (14) may hold. In practice, there are reasons to believe that enforcement costs remain significant even as the prevailing wage rate goes to zero. One is that enforcers may need to be supervised by the owner, who would thus be unable to handle an exceedingly large number of them. Another is that an owner may have to offer enforcers a wage higher than the prevailing one in order to "buy" honesty. Finally, enforcement may simply be impossible without some complementary equipment. More generally, this remark raises empirical issues which cannot be resolved here but underscores the importance of the properties of enforcement activities.

A complete proof of proposition 5 is provided in the appendix. But in order to bring out the roles played by condition (14) and that of stock externalities, it is enlightening to consider it in the following more intuitive terms.

Note first that in the hypothetical case where the wage rate is zero, condition (14) forces the owner to leave the site to a free-access exploitation. Indeed, if he does not do so, the average product of the resource $p \phi(l)$ will be positive, thereby driving enforcement costs to $c(r, 0) \psi(1 / \gamma)$ which, by (14), necessarily results in a net loss, since $p \bar{h}$ is the largest possible gross income.

Consider now the case where the wage rate is positive but approaches zero. Whether the resource exhibits stock externalities or not turns out to be critical. In the absence of stock externalities, an owner can indefinitely increase $l$ in order to keep the average product $p \phi(l)$ small enough without jeopardizing the output. But it is not so when stock externalities are present. In such a case, increases in $l$ will sooner or later be matched by lower output and, for finite $l=\bar{x}$, are driven to zero. More precisely, as the wage rate becomes sufficiently small, increases in $l$ aimed at containing enforcement costs will drive gross profits $(p \phi(l)-w) l$ to zero at a faster rate than enforcement costs. This can be seen most clearly from the following: ${ }^{20}$

$$
\lim _{l \rightarrow l_{F}} \frac{1-\frac{w}{p \phi(l)}}{(p \phi(l)-w) l}=\frac{1}{w l_{F}},
$$

\footnotetext{
${ }^{20}$ Expression (15) is derived using L'Hospital rule.
} 
and thus, $l_{F}$ being finite when stock externalities are present,

$$
\lim _{\substack{l \rightarrow l_{F} \\ w \rightarrow 0}} \frac{1-\frac{w}{p \phi(l)}}{(p \phi(l)-w) l}=\frac{1}{w l_{F}}=+\infty .
$$

Recall, from (10), that enforcement costs will be strictly positive whenever $1-w / p \phi(l)>0$ and that $c(r, w)$ must be strictly positive for any $w$ if condition (14) holds. Obviously, an owner will incur a loss if gross profits are zero while enforcement costs are strictly positive. Expressions (15) and (16) show that as the wage rate becomes sufficiently small, a strategy of increasing $l$ towards the free-access value $l_{F}$, i.e. $p \phi\left(l_{F}\right)=w$, can only lead to a net loss for the owner, unless $l$ is exactly equal to $l_{F}$. But this corresponds to free access. Hence, for some range of sufficiently small wage rates, exclusive ownership will not pay.

Profits must of course also decline to zero as the wage rate becomes too high. In the light of proposition 5, we can assert the following:

Corollary 6 The profit function is non-monotonous relative to the wage rate if condition (14) holds and if the resource exhibits stock externalities.

These results regarding the possible behavior of equilibrium profits as the wage rate varies carry interesting implications for the study of property rights determination and natural-resource exploitation in less-developed countries, or in the economic history of industrialized countries. It provides an economic rationale for the lack of well-defined property rights in those economies as compared to industrialized countries. Figure 2 suggests that for a less-developed country with comparatively low wages, incentives to enclose natural-resource sites tend to be weak. For higher wages, say around $\tilde{w}$, incentives to exclude are more important. It must be stressed that these conclusions do not rest on any exogenous institutional or cultural differences. Given individuals' latent threat to extract illegally, economic agents may be making the most efficient decision by leaving access to some resources open to all. Any added profit resulting from a reduced level of exploitation would be exceeded by larger enforcement costs at $w \leq \underline{w}$. In this case, distributing titles to hitherto free-access natural-resource sites as a means of reducing the intensity of exploitation would result in wasted energies as the new owners would find no economic justification to actually protect the sites from illegal extraction.

The presence of stock externalities as a necessary condition for the foregoing conclusions enables us to propose the following: 


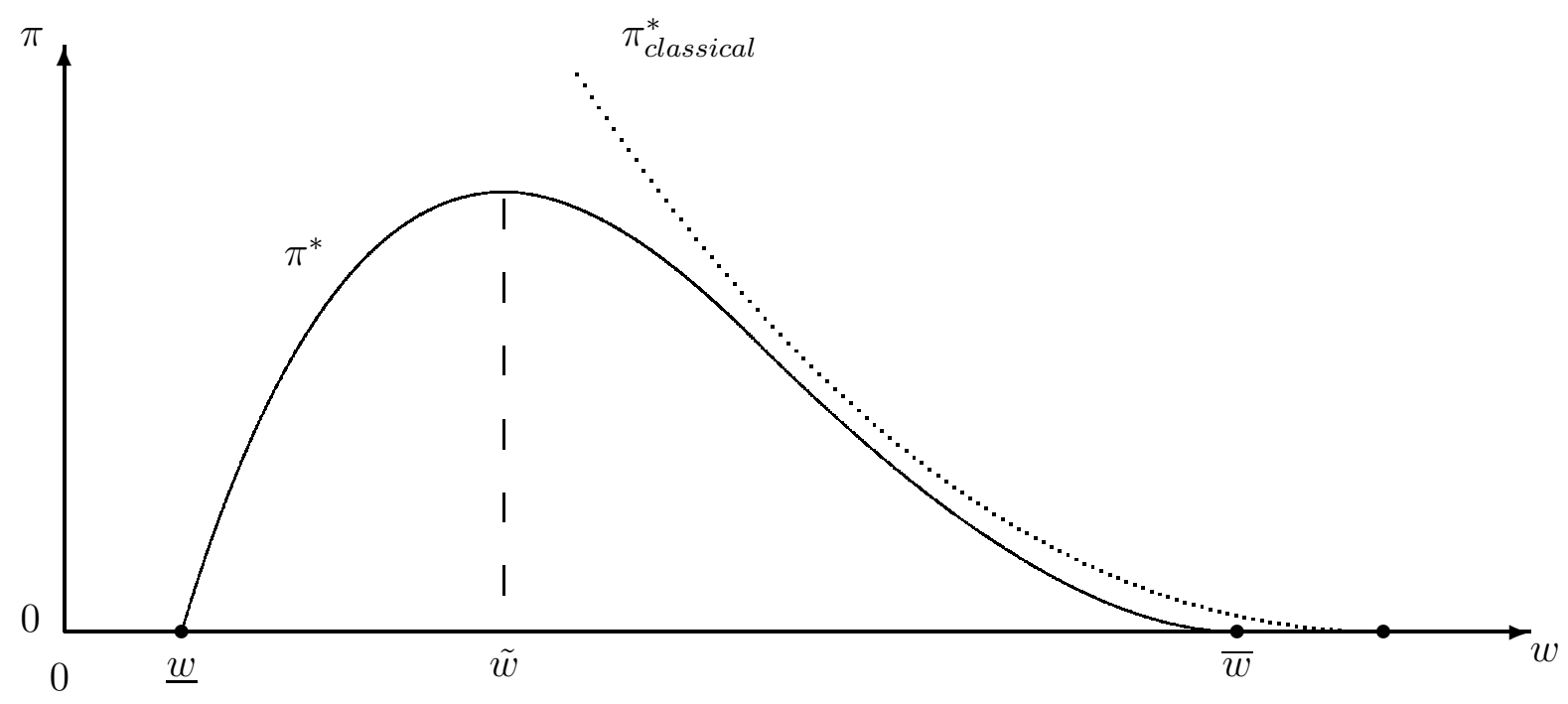

Figure 2: Profits as a function of wage in the presence of stock externalities 
Corollary 7 A reduced wage rate will never lead to the abandonment of a resource site by its owner if the resource exhibits only crowding externalities.

Proposition 5 and Corollaries 6 and 7 imply together that whether we observe more or less free access over natural resources in low-income economies will depend on the dynamic behavior of the resource. Marked differences in actual property regimes between the North and the South should be observed only in the case of resources that exhibit stock externalities.

\subsection{The effects of an increase in resource price on the decision to enforce property rights}

In a fundamental paper in the economic analysis of property rights, Demsetz (1967) conjectures that an increase in the value of a resource is likely to lead, ceteris paribus, to a better delineation of property rights. He illustrates his point by mentioning a study of the Montagnais Indians in Québec which "established the fact that a close relationship existed, both historically and geographically, between the development of private rights in land and the development of the commercial fur trade." (Demsetz 1967, p. 351) Surmising that the advent of the fur trade resulted in an increase in the value of furs, the study supports his conjecture. Nevertheless, in his Economic analysis of property rights, Barzel (1989) points out that Demsetz's conjecture may not always hold. He does recognize that on the one hand, an increase in the value of a resource leads to a higher return from delineation. But on the other hand, incentives for theft are also made higher, thus increasing the costs of policing. There is a priori no reason to believe that the first effect will prevail over the second one.

The following proposition asserts that, within the present framework, Barzel's point turns out not to be valid.

Proposition 8 An increase in the price of the resource cannot lead to the abandonment of exclusive ownership.

Proof: Suppose that at some initial price $p_{0}$ and wage rate $w$, an owner maximizes her profits by choosing to employ $l_{0}$ workers. Assuming positive profits, this site is operated under private ownership. I will now demonstrate that, ceteris paribus, an increase in the resource price cannot lead to a reduction in equilibrium profits from private ownership. Hence, it cannot lead to the abandonment of a site to free access. 
Let the price of the resource increase to $p_{1}>p_{0}$ while keeping the wage rate constant. Although it may not be her profit maximizing choice, the owner could then always choose to employ $l_{1}$ workers in order to satisfy $p_{1} \phi\left(l_{1}\right)=p_{0} \phi\left(l_{0}\right)$, i.e. such that enforcement costs remain the same. Inserting this into the profit function, we get the following inequality

$$
\begin{aligned}
\pi_{0} & =\left[p_{0} \phi\left(l_{0}\right)-w\right] l_{0}-c(r, w) \psi\left(\frac{1}{\gamma}\left(1-\frac{w}{p_{0} \phi\left(l_{0}\right)}\right)\right) \\
& <\left[p_{1} \phi\left(l_{1}\right)-w\right] l_{1}-c(r, w) \psi\left(\frac{1}{\gamma}\left(1-\frac{w}{p_{1} \phi\left(l_{1}\right)}\right)\right)=\pi_{1},
\end{aligned}
$$

since $p_{1} \phi\left(l_{1}\right)=p_{0} \phi\left(l_{0}\right)$ implies $l_{1}>l_{0}$ when $p_{1}>p_{0}$. QED

The intuition behind the above result is that even though the value of the resource has increased, the owner could always keep enforcement costs the same by reducing the attractiveness of the resource through an adjustment in the average productivity of labor. In effect, it is as if the new price structure allowed the owner to replicate the old one by resorting to some form of "destruction of value". ${ }^{21}$ The point is that the initial relative values remain an option at the new higher prices, but the reverse is not true.

\section{Conclusion}

In his seminal paper on property rights, Steven Cheung posed the following question: "Why do exclusive rights not exist for certain actions? Because of the legal institutions, or because policing costs are prohibitive?" (Cheung 1970, p. 58) The role played by the first part of the answer, legal institutions, is now fairly well recognized. A well-known case is the English enclosure

\footnotetext{
${ }^{21}$ I surmise that a similar reasoning would apply to the case presented in Barzel (1989, p. 67). Barzel points out that in a theater with bad and good tickets, it is not possible to say if a doubling in the value of all tickets will lead to a better delineation in prices. He argues that on the one hand, "the difference in valuation between a bad and a good seat would double, too, and therefore the return from pricing the difference would increase... however, the costs of policing would also increase, ... [since] people would gain more from stealing the difference, by buying tickets from the low-priced seats, for instance, and then attempting to occupy the higher priced ones." (Barzel 1989, p. 67). What the present model suggests is that the theater's managers could always replicate the previous price differences either by reducing the relative value of the better seats (making them less comfortable) or by reducing the value of all seats (hiring less famous actors).

It has similarly been argued that adding a positive probability of being evicted from their land may lead owners to destroy value. (Innes 1997, Innes et al. 1998, Hotte 2001)
} 
movement of the eighteenth century, attributed mostly to a parliamentary statute which substantially reduced the fixed costs associated with enclosure (McCloskey 1975). By contrast, similar attempts at privatizing the commons in Old Regime France met little success due to high litigation costs which are attributed to the lack of support from a central authority (Rosenthal 1992). In this paper, however, the set of legal institutions was assumed constant in order to consider the second part of the answer to Cheung's question, i.e. the role played by policing costs. To this end, I proposed a framework from which to address the problem of natural resource exploitation when private ownership calls for costly enforcement activities.

Enforcement costs were endogenized by explicitly describing individuals' incentives to illegally extract on a resource site. It was shown that the equilibrium level of exploitation chosen by the owner exceeds that for which the value of marginal product of labor equals the wage rate. This is so, even though no illegal extraction occurs in equilibrium. At first sight, it may thus seem that the owner of a site overexploits her resources. But when the endogenous enforcement costs are accounted for, it becomes clear that this may not be the case. The intuition is that an owner has two ways of discouraging outsiders: she can either raise the probability of detection with larger enforcement expenditures, or she can reduce the returns from illegal activities by increasing the intensity of exploitation, thus lowering labor's value of average product on the site. In equilibrium, the owner will use a combination of both, with the result that the marginal social cost of the resource may still be above its price even in the presence of private property.

It was also shown how, under certain conditions, reductions in the wage rate may actually result in lower equilibrium profits. This is explained by the fact that when the legal wage rate of an economy is already quite low, further reductions so severely foster incentives to extract illegally that increased enforcement costs outpace any additional direct profit from exploitation. Moreover, there exists a threshold level of the legal wage rate below which positive profits become impossible to achieve, with the result that the site is left to free access. The simple conditions necessary for these results to obtain turn out to be quite compatible with many types of renewable resources.

Considering that wages are usually lower in less-developed economies, the analysis provides a formal explanation as to why their property rights on natural-resource sites are not so well delineated as in industrialized economies. In some circumstances, the delineation of property rights may be viewed as a response of agents to endogenous economic variables rather than a response 
to different institutions. In this respect, some policy prescriptions that foster private ownership in less-developed countries in order to replicate their industrialized counterparts may end up being more costly than beneficial. Moreover, the distribution of a title to a previously unclaimed resource site may not prevent it from being exploited as a free-access resource.

It was also shown that an increase in the price of the resource cannot lead to a worse delineation of property rights. This is because with the new higher price, an owner can always reduce the value of the resource to its original value in order to keep enforcement costs at the same level. The insight behind this result may have more general implications: when the enforcement of private property entails important expenditures, owners may resort to "destroying" the value of their property in order to lower enforcement expenditures. In a general equilibrium, this is likely to create distortions which may be worth investigating further. For instance, the losses from trade present in Brander and Taylor's (1997a, 1998a) analysis may still obtain with private property.

Allowing property right arrangements to depend on the wage rate brings up the following question: Is a better delineation of property rights a prerequisite to economic growth or is it the other way around? The foregoing analysis suggests that they go hand in hand. Economic growth, when associated with an increase in wages, will reduce the pressure from outsiders and thus lead to a better delineation of property rights. The ensuing gain in efficiency in the exploitation of natural resources should promote growth further. How this works out exactly will require a general-equilibrium analysis and goes beyond the scope of this study.

A second line of research which is suggested by the above analysis has to do with the distribution of wealth. It was assumed, all along, that workers' income originated solely from their labor wages. There may be a case, here, for a Pareto improvement resulting from a better distribution of property ownership between site owners and workers. By claiming a share of the rents from resource sites, workers' income will increase, thereby reducing enforcement costs for the exploitation of the sites. For the owners, the gains from reductions in enforcement costs may outweigh the forsaken shares of the rents. ${ }^{22}$

\footnotetext{
${ }^{22}$ An interesting study which tends to support this beneficial effect resulting from a better distribution of wealth is that of Johnsen (1986). The author argues that the Southern Kwakiutl Amerindians of the Canadian West Coast, whose wealth depends mostly on salmon, made use of a custom called the Potlatch system as a way to reduce incentives
} 
Another aspect which has been eschewed is the optimality of private decisions to enclose resource sites and the optimal amount of government support. One would think that the government could make it easier for owners to exclude outsiders, but at what cost? What is the nature of the government's intervention? Is it a substitute or a complement to an owner's enforcement activities?

Finally, the model proposes a framework from which to study the effects of international trade on natural-resource exploitation, assuming that property rights are endogenously determined (see Hotte, Long and Tian, 2000). The model may be adapted to study the effects of international trade on the environment in a similar framework.

\section{Acknowledgements}

I wish to thank especially Gérard Gaudet for his comments. Earlier drafts also benefited from comments by participants at the 1997 Colloquium on Natural Resources and Environmental Economics at Université Laval, as well as Nancy Bergeron, Pascal Favard, André Martens, Jean-Philippe Platteau, Michel Poitevin, Stephen Salant, Yves Sprumont, Fabrice Valognes, anonymous referees, and participants at various seminars and conferences at the Universities of Namur, Montreal, Cergy-Pontoise, Exeter, and Universidad de los Andes in Bogotá. Remaining errors are mine. This research was conducted partly under the auspices of the PARADI program which links the C.R.D.E. at Université de Montréal and CRÉFA at Université Laval, and which is financed as a Center of excellence in international development by the Canadian Agency for International Development.

for members of one group to extract illegally upon another's salmon fishery. The Potlatch consisted of a ceremony where gifts of significant value were exchanged, thus amounting to a redistribution of income. A Potlatch host gained social status proportional to his generosity. As the author notes, the system could only function because salmon being fished in rivers, the territories were relatively easy to protect from outside extraction; this was not the case for Amerindians of the interior who depend mostly on buffalo and antelope, which dwelt over large open areas. 


\section{APPENDIX}

\section{A Proof of proposition 5}

\section{A.1 Proof of part a) of proposition 5}

The proof consists in showing that as the wage rate tends to zero, the best an owner can do is to hire labor such that its average productivity becomes equal to the wage rate, which drives profits to zero. There are two cases to consider: one in which $\lim _{w \rightarrow 0} l<\bar{x}$, the other in which $\lim _{w \rightarrow 0} l=\bar{x}$.

In the first case, with $l<\bar{x}$, we have $\phi(l)>0$ and hence

$$
\lim _{w \rightarrow 0} \pi=p h(l)-c(r, 0) \psi\left(\frac{1}{\gamma}\right)
$$

From condition (14), profits are then strictly negative.

Consider now the case in which $\lim _{w \rightarrow 0} l=\bar{x}$, but in such a way that $\lim _{w \rightarrow 0} w / p \phi(l)=\varepsilon$, with $0<\varepsilon<1$. This implies $\lim _{w \rightarrow 0} h(l)=0$ and thus

$$
\lim _{w \rightarrow 0} \pi=-c(r, 0) \psi\left(\frac{1}{\gamma}(1-\varepsilon)\right)<0 .
$$

The owner can improve on both cases by choosing $l$ such that $\lim _{w \rightarrow 0} w / p \phi(l)=$ 1 , which implies $\lim _{w \rightarrow 0} \pi=0$. This result is essentially equivalent to a free access to the resource.

This completes the proof that condition (14), combined with the fact that the resource exhibits stock externalities, are sufficient conditions for part a) of the proposition to hold. The following lemma will be useful:

Lemma 9 If the resource exhibits stock externalities and condition (14) holds, then an owner will choose $l$ such that

$$
\lim _{w \rightarrow 0} \frac{w}{p \phi(l)}=1
$$

\section{A.2 Proof of part b) of proposition 5}

The strategy of the proof is as follows. 
The sufficiency condition: I first demonstrate, in part i), that if strictly positive profits are possible at all, then the first-order condition in (12) constitutes a necessary condition for a maximum. In part ii), I argue that since this is true for any wage rate, it must remain true as the wage rate tends to zero. I then show that this leads to a contradiction. Hence, for sufficiently small wage rates, profits cannot be positive. Negative profits are also ruled out since free-access is always an option.

The necessary condition: I proceed by showing, in part iii), that if condition (14) does not hold, then positive profits can be achieved as the wage rate goes to zero, and in part iv) that if the output of the resource is nondecreasing in $x$, then profits will never decrease as the wage rate decreases.

\section{A.2.1 The sufficiency condition}

i) Demonstration that first-order condition (12) constitutes a necessary condition for a maximum with positive profits.

Let $l_{F}$ be the free-access amount of labor, i.e. $p \phi\left(l_{F}\right)=w$, and let $l_{P}$ be the amount of labor that would be hired in the case of perfectly and costlessly defined property rights, i.e. $p h^{\prime}\left(l_{P}\right)=w$. Profits are zero at $l_{F}$ and it is easy to verify that $\partial \pi / \partial l>0$ for all $l \leq l_{P}$. By continuity of the profit function, it can thus be asserted that if profits are anywhere positive, there must exist a global maximum, say at $l^{*}$, characterized by $\partial \pi / \partial l=0$, and such that $l_{P}<l^{*}<l_{F}$.

ii) We proceed by contradiction by showing that although the profit function approaches zero as the wage rate goes to zero, it does so neither from above, nor from below.

Assume that $\pi>0$ for all $w \in(0, \bar{w})$, where $\bar{w}$ represents the maximum wage rate for which positive profits are possible. From Lemma 9, we know that profits are zero at $w=0$. This implies that as the wage rate goes to zero, the profit function approaches zero from above. Hence, from part i), we must have $\lim _{w \rightarrow 0} l^{*}=l_{F}=\bar{x}$ and $\lim _{w \rightarrow 0}(\partial \pi / \partial l)=0$ at $l^{*}=\bar{x}$. But

$$
\left.\frac{\partial \pi}{\partial l}\right|_{\substack{w=0 \\ l=\bar{x}}}=p h^{\prime}(\bar{x})-c(r, 0) \psi^{\prime}(0) \frac{\phi^{\prime}(\bar{x})}{\gamma \phi(\bar{x})}=+\infty,
$$


since $\phi(\bar{x})=0$. A contradiction.

Hence, as the wage rate goes to zero, the profit function cannot approach zero from above. And since one can always set $l=l_{F}$, the profit function cannot approach zero from below either. It must be the case, then, that as the wage rate goes to zero, profits are zero for some posive range of the wage rates, say $w \in(0, \underline{w})$, where $\underline{w}$ is characterized by $\partial \pi / \partial l=0$ and $\pi=0$.

\section{A.2.2 The necessary condition}

iii) If condition (14) does not hold, then, as the wage rate goes to zero, it is easy to verify that if an owner always chooses $x=\tilde{x}$, profits are strictly positive. Hence, condition (14) is necessary.

iv) Assume that the output function is non-decreasing and suppose that at some $w_{0}>0$, profits are positive. Let the wage rate decrease to $w_{1}<w_{0}$ and choose $l_{1}$ such that

$$
\frac{w_{0}}{p \phi\left(l_{0}\right)}=\frac{w_{1}}{p \phi\left(l_{1}\right)}
$$

This implies that enforcement costs have not increased, and that $l_{1}>l_{0}$ and $h\left(l_{1}\right) \geq h\left(l_{0}\right)$. But from (18), we have

$$
\frac{w_{0} l_{0}}{p h\left(l_{0}\right)}=\frac{w_{1} l_{1}}{p h\left(l_{1}\right)},
$$

which implies that $p h\left(l_{1}\right)-w_{1} l_{1} \geq p h\left(l_{0}\right)-w_{0} l_{0}$ since, for any $a, b>0, b>a$,

$$
\frac{a}{b}=\frac{\alpha a}{\alpha b}<1 \text { and } \alpha>1 \Rightarrow \alpha b-\alpha a=\alpha(b-a)>b-a .
$$

Hence, following the decrease in the wage rate, gross profits have not decreased while enforcement costs have not increased. Net profits have thus not decreased with the lower wage rate. 


\section{References}

[1] Terry L. Anderson and P. J. Hill. The evolution of property rights: A study of the american west. The Journal of Law and Economics, 18:163-179, April 1975.

[2] Yoram Barzel. Economic Analysis of Property Rights. Cambridge University Press, Cambridge, England, 1989.

[3] William J. Baumol and Wallace E. Oates. The theory of environmental policy. Cambridge University Press, Cambridge, England, 2 edition, 1988.

[4] Gary S. Becker. Crime and punishment: An economic approach. Journal of Political Economy, 76:169-217, March-April 1968.

[5] Timothy Besley. Property rights and investments incentives: Theory and evidence from ghana. Journal of Political Economy, 103(5):903937, 1995.

[6] James A. Brander and M. Scott Taylor. International trade and open access renewable resources: The small open economy case. Canadian Journal of Economics, XXX(3):526-552, August 1997.

[7] James A. Brander and M. Scott Taylor. International trade between consumer and conservationist countries. Resource and Energy Economics, 19:267-297, November 1997.

[8] James A. Brander and M. Scott Taylor. Open access renewable resources: Trade and trade policy in a two-country model. Journal of International Economics, 44:181-209, April 1998.

[9] James A. Brander and M. Scott Taylor. The simple economics of easter island: A ricardo-malthus model of renewable resource use. American Economic Review, 88(1):119-138, march 1998.

[10] Robin Brooks, Michael Murray, Stephen Salant, and Jill C. Weise. When is the standard analysis of common property extraction under free access correct? a game-theoretic justification for non-game-theoretic analyses. Journal of Political Economy, 107(4):843-858, 1999. 
[11] Gardner M. Brown. Renewable natural resource management and use without markets. Journal of Economic Literature, XXXVIII:875-914, December 2000.

[12] Steven N. S. Cheung. The structure of a contract and the theory of a non-exclusive resource. Journal of Law and Economics, XIII:45-70, 1970 .

[13] Graciela Chichilnisky. North-south trade and the global environment. The American Economic Review, 84(4):851-874, September 1994.

[14] C.W. Clark. Mathematical Bioeconomics. Wiley, New York, 1976.

[15] Harry R. Clarke, William J. Reed, and Ram M. Shrestha. Optimal enforcement of property rights on developing country forests subject to illegal logging. Resource and Energy Economics, 15:271-293, 1993.

[16] Jon S. Cohen and Martin L. Weitzman. A marxian model of enclosures. Journal of Development Economics, 1:287-336, 1975.

[17] Philippe Crabbé and Ngo Van Long. Entry deterrence and overexploitation of the fishery. Journal of Economic Dynamics and Control, pages 679-704, 1993.

[18] P. S. Dasgupta and G. M. Heal. Economic Theory and Exhaustible Resources. James Nisbet and Co. Ltd and Cambridge University Press, Welwyn, England, 1979.

[19] David de Meza and J.R. Gould. The social efficiency of private decisions to enforce property rights. Journal of Political Economy, 100(3):561580, 1992.

[20] Harold Demsetz. Toward a theory of property rights. American Economic Review, 57:347-359, 1967.

[21] Isaac Ehrlich. Participation in illegitimate activities: A theoretical and empirical investigation. Journal of Political Economy, 81:521-565, 1973.

[22] Barry C. Field. The evolution of property rights. KYKLOS, 42(3):319345, 1989. 
[23] Kathryn Firmin-Sellers. The politics of property rights. American Political Science Review, 89(4):867-881, December 1995.

[24] David Friedman and William Sjostrom. Hanged for a sheep - the economics of marginal deterrence. Journal of Legal Studies, XXII:345-366, June 1993.

[25] H. Scott Gordon. The economic theory of a common-property resource: The fishery. Journal of Political Economy, VXII:124-142, April 1954.

[26] Garrett Hardin. The tragedy of the commons. Science, 162:1243-1248, December 1968.

[27] J. M. Heineke. Substitution among crimes and the question of deterrence: An indirect utility function approach to the supply of legal and illegal activity. In J. M. Heineke, editor, Economic Models of Criminal Behavior, chapter 5, pages 153-209. North-Holland Publishing Company, 1978.

[28] Robert W. Helsley and William C. Strange. Exclusion and the private enforcement of property rights. Journal of Public Economics, 53:291308, 1994.

[29] Louis Hotte. Conflicts over property rights and natural-resource exploitation at the frontier. Journal of Development Economics, 66:1-21, 2001.

[30] Louis Hotte, Ngo Van Long, and Huilan Tian. International trade with endogenous enforcement of property rights. Journal of Development Economics, 62:25-54, 2000.

[31] Robert Innes. Takings, compensation, and equal treatment for owners of developed and undeveloped property. Journal of Law and Economics, XL:403-432, 1997.

[32] Robert Innes, Stephen Polasky, and John Tschirhart. Takings, compensation and endangered species protection on private land. Journal of Economic Perspective, 12:35-52, 1998.

[33] D. Bruce Johnsen. The formation and protection of property rights among the southern kwakiutl indians. Journal of Legal Studies, XV:4167, January 1986. 
[34] R.N. Johnson and G.D. Libecap. Agency costs and the assignment of property rights: The case of southwestern indian reservations. Southern Economic Journal, 47(2):332-347, October 1980.

[35] Pierre Lasserre. Protection décentralisée des droits de propriété, police et justice. L'Actualité économique, Revue d'analyse économique, 70(2):177-189, juin 1994.

[36] Donald N. McCloskey. The economics of enclosure: A market analysis. In William N. Parker and Eric L. Jones, editors, European Peasants and Their Markets: Essays in Agrarian Economic History, pages 123-160. Princeton University Press, Princeton, New Jersey, 1975.

[37] Scott R. Milliman. Optimal fishery management in the presence of illegal activity. Journal of Environmental Economics and Management, 13:363-381, 1986.

[38] Douglass C. North. Institutions, Institutional Change and Economic Performance. Cambridge University Press, Cambridge, England, 1990.

[39] Elinor Ostrom. Governing the Commons: The evolution of institutions for collective action. Cambridge University Press, Cambridge, England, 1990.

[40] Jean-Laurent Rosenthal. The Fruits of Revolution: Property Rights, litigation, and French Agriculture, 1700-1860. Cambridge University Press, Cambridge, England, 1995.

[41] Vernon L. Smith. Economics of production from natural resources. American Economic Review, 56:409-31, 1968.

[42] George J. Stigler. The optimum enforcement of laws. Journal of Political Economy, 78:526-536, 1970.

[43] Jon G. Sutinen and Peter Anderson. The economics of fisheries law enforcement. Land Economics, 61(4):387-397, November 1985.

[44] Thomas H. Tietenberg. Environmental and Natural Resource Economics. HarperCollins College Publishers, New-York, 1996. 
[45] Aarón Tornell and Andrés Velasco. The tragedy of the commons and economic growth: Why does capital flow from poor to rich countries? Journal of Political Economy, 100(6):1208-1231, 1992.

[46] Caroline Van Rijckeghem and Beatrice Weder. Corruption and the rate of temptation: Do low wages in the civil service cause corruption? IMF Working Paper WP/97/73, International Monetary Fund, June 1997.

[47] Hal R. Varian. Microeconomic analysis. W. W. Norton and Company, third edition, 1992.

[48] World Bank. World Development Report: Development and the Environment. Oxford University Press, Oxford, 1992. 